\title{
MODELLING OF THERMAL PROCESSES IN BARRIER OZONIZER USED IN BEEKEEPING
}

\author{
Sergei Oskin, Sergey Nikolaenko, Alexander Voloshin, Dmitry Tsokur \\ Kuban State Agrarian University named after I.T. Trubilin, Russia \\ kgauem@yandex.ru,211521152115@mail.ru, luntik-s@mail.ru,dmitry_tsokur@mail.ru
}

\begin{abstract}
The use of ozonizers is important for disinfection of bee hives and bee equipment, as well as for prevention and treatment of bacterial diseases of bees. The main parameter affecting the operation of the ozonizer is the temperature of dielectric barriers of its discharge device. The present analysis of existing thermal models has shown that, despite numerous studies, there is currently no mathematical model of thermal processes in the ozonizer that would take into account its design parameters (material, size, number of sections), gas flow mode, convective heat exchange with the environment and would allow us to study the change in temperature fields throughout the entire volume of the installation over time. The geometric model of the barrier ozonizer and the stages of creating its thermal model are described in detail in the article. Mathematical processing of the resulting model was performed using the Comsol Multiphysics 5.4 program. The features of modelling in this program aimed at reducing the calculation area and calculation time are considered. Mathematical processing of the resulting model was carried out in two stages: first, a stationary air velocity field was calculated, and then a non-stationary thermal problem was solved. It is determined that this approach significantly saves computing resources. As a result of the calculation, the surfaces of temperature distribution in the entire volume of the ozonizer over time are obtained. To check the adequacy of the developed model, the ozonizer was manufactured on the upper surface of the discharge device, which had 3 temperature sensors installed. Comparison of the obtained theoretical and experimental data showed good convergence, which indicates the adequacy of the obtained mathematical model of thermal processes in the ozonizer and the possibility of its further use for improving ozonizers in beekeeping.
\end{abstract}

Keywords: ozonizer, beekeeping, thermal model, Comsol Multiphysics.

\section{Introduction}

In agriculture, ozonizers are used for many purposes. For example, they are used for drying and storage of grain, pre-sowing treatment of seeds, water disinfection, pest control, as well as for creating a microclimate indoors and for many other purposes [1-6]. Also, one of the promising uses of ozone is its application for prevention and treatment of bacterial diseases of bees. Due to such wide use of ozonizers in agriculture, it is very important to increase their efficiency. It is impossible to achieve this without creation of a mathematical model of thermal processes taking place in the ozonizer, as ozonizers often fail because of overheating. The study of the influence of the temperature of the discharge device of the ozonizer on the formation of ozone has been studied by many authors. For example, in the Kuban State Agrarian University, this issue was studied by S. A. Nikolaenko, D. A. Ovsyannikov, and E. A. Denisenko [7-9]. Their mathematical models of thermal processes in the ozonizer take into account the influence of air supply in respect to changes in its physical properties and the temperature of dielectric barriers. These models calculate the temperature of the glass of the dielectric barriers without taking into account the air flow mode in the ozonizer, in addition, it is impossible to see the heat distribution inside the installation. The influence of the air flow mode inside the ozonizer was studied by V. A. Kuznetsov [10-11]. The advantage of ozonizers with a turbulent air flow regime in discharge gaps over ozonizers with a laminar regime was substantiated by him. The thermal models obtained by the author allow us to see the temperature change in the thickness of the discharge gap in its various sections, standing at specified distances from the point of air entry into the ozonizer.

Thus, despite numerous studies of thermal processes in the ozonizer, there is currently no mathematical model that would show the change of thermal fields in the entire volume of the ozonizer over time. To solve this problem, we suggest using the Comsol software product.

\section{Materials and methods}

A plate-type barrier ozonizer was selected as the object of the research, the scheme of which is shown in Figure 1. The main components of the ozonizer used in beekeeping for the prevention and treatment of bacterial diseases of bees are shown in Figure 1. The ozonizer has a cylindrical body 1 made of PVC plastic. Dielectric barriers 2 are made of glass (each dielectric barrier consists of two 
plates of glass). Discharge gaps 4, in which the formation of ozone occurs, are formed due to pieces of glass 5, which are located at the entrance and exit of the ozonizer, as well as in the middle part. As it can be seen from Figure 1, the ozonizer has an inlet and outlet for air supply and output of the ozoneair mixture, respectively.

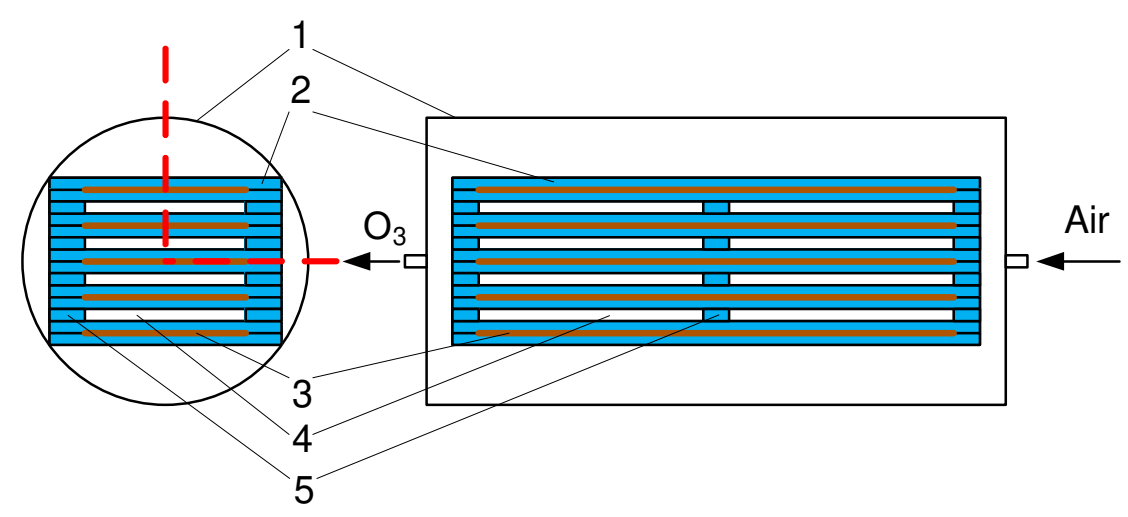

Fig. 1. Plate-type barrier ozonizer: 1 - framework; 2 - dielectric barriers; 3 - electrodes; 4 - discharge gap; 5 - piece of glass

Based on the design of the ozonizer, to reduce the calculation time in the Comsol software product, it is possible to reduce the calculation area by 4 times according to the dotted line shown in Figure 1. Since the simulation of electrical processes will not be performed, the electrodes can be excluded from the model. Thus, the final geometric model of the ozonizer in Comsol will have the form shown in Figure 2.

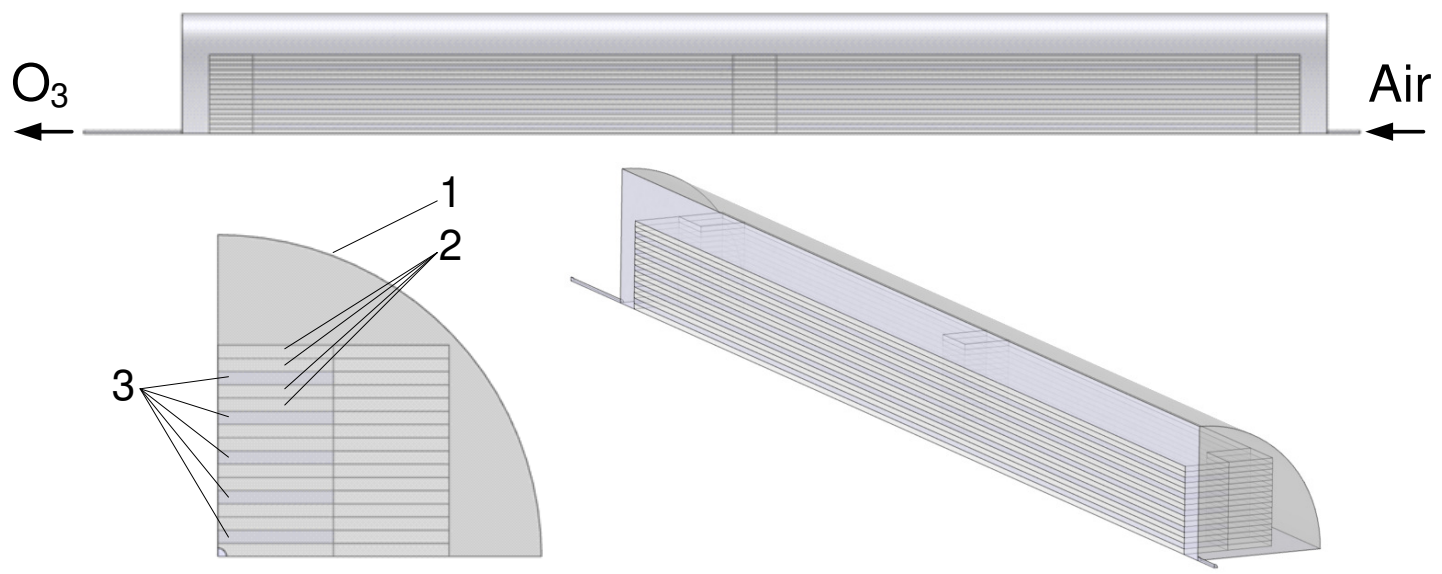

Fig. 2. Geometrical model of the ozonizer in Comsol:

1 - framework of the ozonizer; 2 - dielectric barriers; 3 - discharge gaps

The geometrical model worked out in the program Comsol Multiphysics is shown in Figure 2. The size of the glass plates that make up the dielectric gaps is 500x80x2.3 mm. The discharge gaps are formed by pieces of the same glass plates, so their height is $2.3 \mathrm{~mm}$.

From V. A. Kuznetsov's research, it is known that only $15 \%$ of the energy supplied to the ozonizer is spent on formation of ozone. The remaining $85 \%$ is heat loss. It is known from [12] that the power supplied to the ozonizer is equal to:

$$
P=(2 / \pi) \omega U_{g}\left[C_{b}\left(U_{0}-U_{g}\right)-U_{g} C_{p}\right],
$$

where $\omega=2 \pi f-$ angular frequency of current, $\mathrm{rad} \cdot \mathrm{s}^{-1}$;

$f$ - frequency of current $(f=50 \mathrm{~Hz}), \mathrm{Hz}$;

$U_{g}$ - instantaneous value of the voltage across the discharge gap, B;

$U_{0}$ - amplitude value of the voltage on the ozonizer, B;

$C_{b}$ - capacity of two dielectric barriers connected in series, F;

$C_{p}$ - capacity of the discharge gap, F. 


$$
C_{b}=\frac{\left(\frac{\varepsilon_{0} \varepsilon_{m} S_{m}}{d_{m}}\right)}{2}, C_{p}=\frac{\varepsilon_{0} \varepsilon_{a} S_{a}}{d_{a}}, U_{g}=\frac{C_{s b}}{C_{p}}, C_{s b}=\frac{1}{\frac{1}{C_{p}}+\frac{1}{C_{b}}+\frac{1}{C_{b}}},
$$

where $\varepsilon_{0}$ - electrical constant, numerically equal to $8.854187817 \cdot 10^{-12} \mathrm{~F} \cdot \mathrm{m}^{-1}$;

$\varepsilon_{m}, \varepsilon_{a}$ - dielectric constant of glass $\left(\varepsilon_{m}=4-16\right.$, depending on the glass composition) and dielectric permittivity of air $\left(\varepsilon_{a}=1\right)$ respectively;

$s_{m}, s_{a}$ - area of the glass plate and discharge gap respectively, $\mathrm{m}^{2}$;

$d_{m}, d_{a}$ - thickness of the dielectric barrier and discharge gap respectively, $\mathrm{m}^{2}$;

$C_{s b}$ - total capacity of two dielectric barriers and the discharge gap connected in series, F.

The formula (1) is shown for one discharge gap, therefore, in cases of multiple discharge intervals (they are 10 in this model), you need to multiply the power $\mathrm{P}$ to their number, and 0.85 (the factor that takes into account what portion supplied to the ozonizer, the energy spent on heating).

Thermal conductivity in the space surrounding the dielectric barriers:

$$
\rho C_{p} \frac{\partial T}{\partial t}+\rho C_{p} u \cdot \nabla T+\nabla \cdot q=Q,
$$

where $\rho$-medium density, $\mathrm{kg} \cdot \mathrm{m}^{-3}$;

$C_{p}$ - heat capacity of the medium, $\mathrm{J} \cdot(\mathrm{kg} \cdot \mathrm{K})^{-1}$;

$u$ - field of air velocity blown through the ozonizer, $\mathrm{m} \cdot \mathrm{s}^{-1}$;

$Q$ - capacity of thermal source, $Q=(0.85 \cdot 10 \cdot P) / \mathrm{V}, \mathrm{W} \cdot \mathrm{m}^{-3}$;

$V$ - thermal source volume, $\mathrm{m}^{3}$;

$q$ - thermal flow density $q=-k \nabla T, \mathrm{~W} \cdot \mathrm{m}^{-2}$

$k$ - thermal conductivity of air, $\mathrm{W} \cdot(\mathrm{m} \cdot \mathrm{K})^{-1}$;

$T$ - temperature, $\mathrm{K}$.

Dielectric barriers are thermal sources in the model. Since only a quarter of the installation is involved in the calculation, $Q$ is divided by 4 in the model.

The heat flow in the input into the ozonizer is as follows [13]:

$$
\begin{gathered}
-n \cdot q=\rho \Delta H u \cdot n \\
\Delta H=\int_{T_{u s t r}}^{T} C_{p} d T+\int_{p_{u s t r}}^{p_{A}} \frac{1}{\rho}\left(1-\alpha_{p} T\right) d p,
\end{gathered}
$$

where $n$ - normal vector;

$H$ - enthalpy, $\mathrm{J} \cdot \mathrm{kg}^{-1}$;

$T_{\text {ustr }}$ - external temperature, $T_{\text {ustr }}=22^{\circ} \mathrm{C}$;

$p_{A}-$ absolute pressure, $\mathrm{Pa}$;

$p_{\text {ustr }}$ - external pressure, $\mathrm{Pa}$;

$\alpha_{p}$ - coefficient of thermal extension, ${ }^{\circ} \mathrm{K}^{-1}$.

Since the frame of the ozonizer is made in the form of a cylinder, the heat transfer coefficient $h$ during heat exchange with the environment due to external natural convection [13]:

$$
h=\frac{k}{D}\left(0.6+\frac{0.387 R a^{1 / 6}}{\left(1+\left(\frac{0.559}{P r}\right)^{9 / 16}\right)^{8 / 27}}\right)^{2}
$$

where $k$-thermal conductivity, $\mathrm{W} \cdot(\mathrm{m} \cdot \mathrm{K})^{-1}$;

$D$ - diameter of the ozonizer framework, $\mathrm{m}$;

$R a$ - Rayleigh number associated with the cylinder diameter $D$; 
$\operatorname{Pr}$ - Prandtl number.

$$
R a=\frac{g \alpha_{p} \rho^{2} C_{p}\left|T-T_{e x t}\right| D^{3}}{k \mu},
$$

where $g$-acceleration of gravity, $\mathrm{m} \cdot \mathrm{s}^{-2}$;

$T_{\text {ext }}$ - external temperature, $\mathrm{K}$.

$\mu$-dynamic viscosity, Pa.s.

The algebraic Plus turbulence model, most commonly used for simulating cooling of electrical installations, was used to model the air flow [14].

To reduce the calculation time, the framework of the ozonizer is made in the form of a thin layer. At the beginning of the simulation, the input and output of the ozonizer were made in the form of holes in the framework, but as it turned out for better convergence of the model, it was necessary to replace these holes with input and output sections of pipes.

Since the air heating is insignificant in the problem, the influence of temperature on the velocity and pressure field can be ignored. In this case, the problem can be solved sequentially: first calculate the stationary velocity field, and then solve the non-stationary thermal problem. This approach significantly reduces the calculation time and saves computing resources.

The ozonizer was manufactured on the upper surface of the discharge device, which had 3 temperature sensors installed in the form of thermal resistances to check the adequacy of the developed model. Such ozonizers are used for prevention and treatment of bacterial diseases of bees in Krasnodar Territory - the southernmost region of the Russian Federation (Fig 3). The sensors were installed evenly along the entire length of the discharge device (sensor 2 is located in the middle, sensors 1 and 3 at a distance of $3 \mathrm{~cm}$ from opposite sides of the discharge device, as shown in Figure 4).

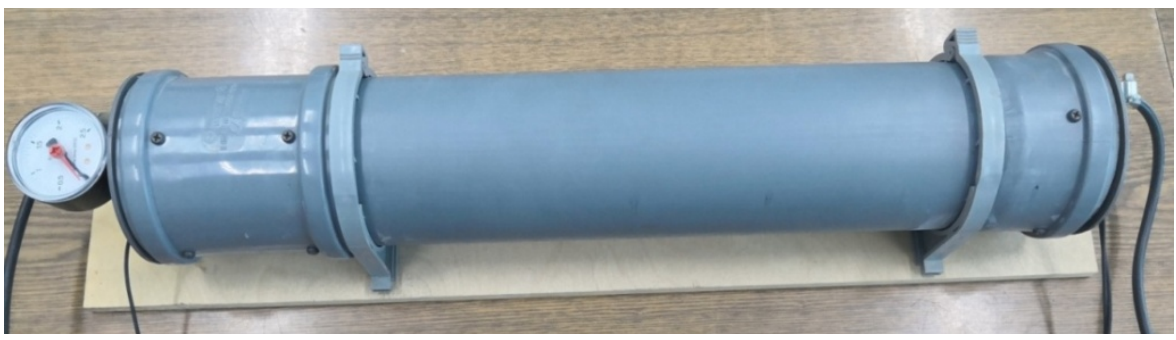

Fig. 3. Ozonizer for disinfection of beehives

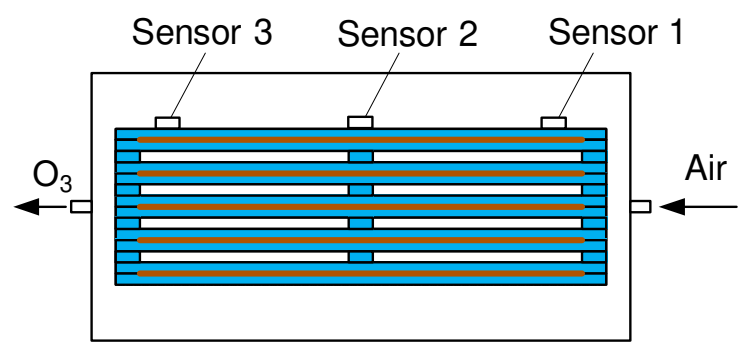

Fig. 4. Location of temperature sensors inside the ozonizer

\section{Results and discussion}

As a result of the calculation of the model developed in the Comsol Multiphysics program, the surfaces of temperature distribution in the ozonizer over time are obtained. In Figure 5 uneven heating is visible along the discharge device of the ozonizer after 5, 60 and 120 minutes of its operation. Temperatures above $50{ }^{\circ} \mathrm{C}$ are unavailable, as they lead to a sharp drop in the concentration of ozone at the outlet of the ozonizer. During the analysis of the data obtained after the simulation, it was determined that the ozonizer begins to overheat after 85 minutes. The ozonizer overheats inside the discharge device at a distance of $42 \mathrm{~cm}$ from the inlet. 

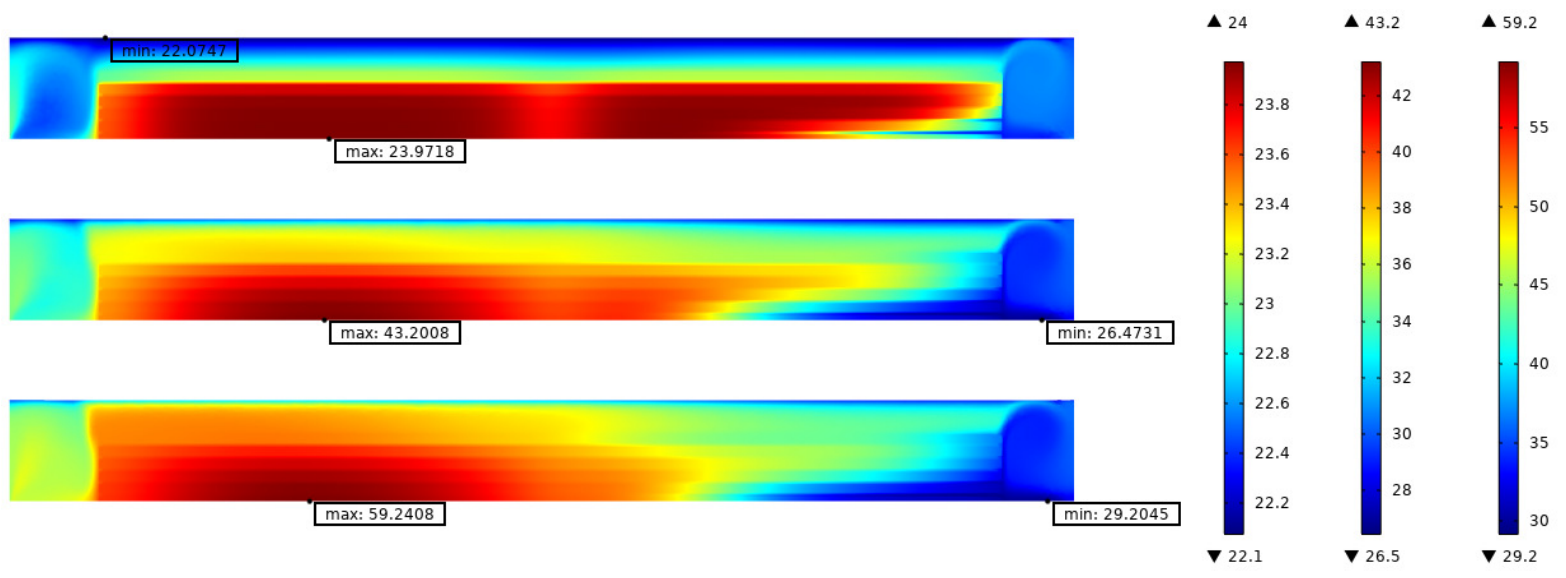

Fig. 5. Surface and distribution of temperatures in the ozonizer: above - in $5 \mathrm{~min}$, in the middle - in $60 \mathrm{~min}$, down - in $120 \mathrm{~min}$

The experimental installation operated for 2 hours, during which the temperature sensors were read out. The temperature graphs obtained during the experiment and from the model are shown in Figure 6 . The diagram shows a small discrepancy between the experimental data and the data obtained during the simulation, most likely due to measurement errors and coefficients accepted in the model.

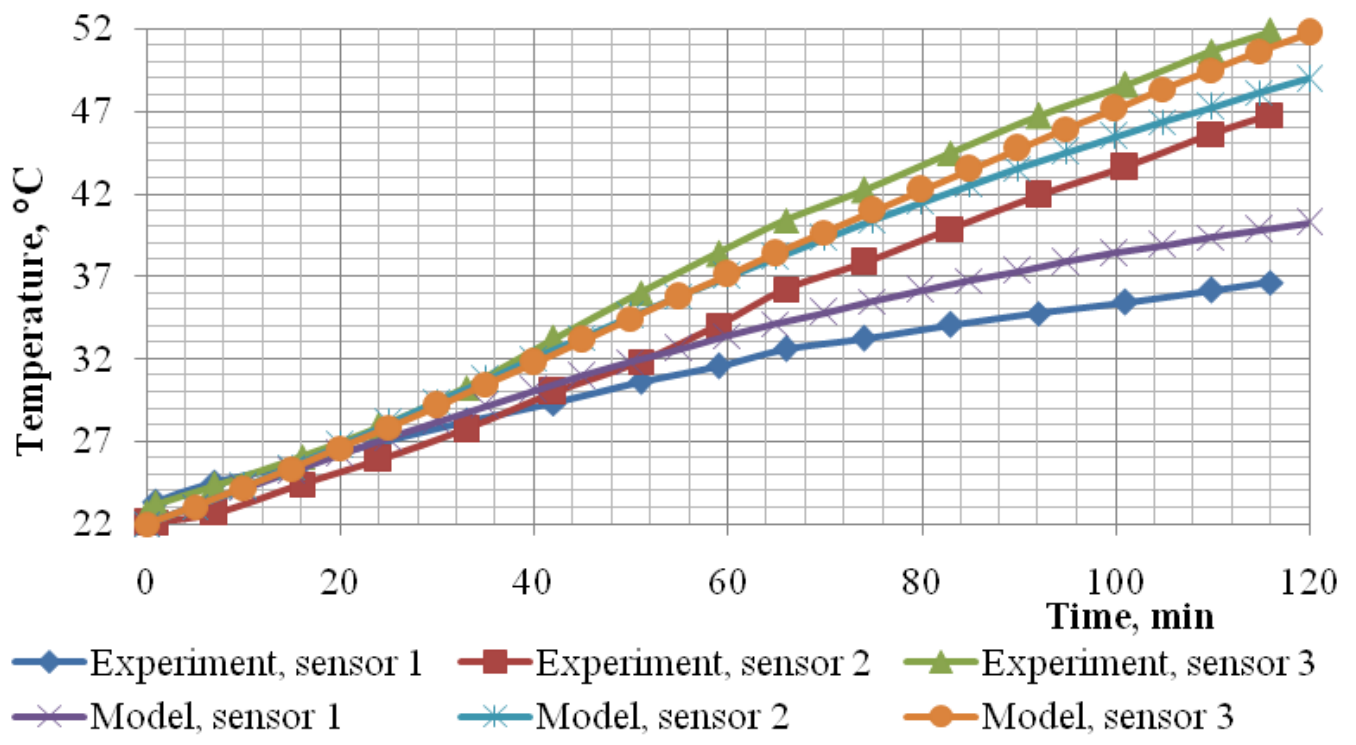

Fig. 6. Comparison of temperature graphs obtained experimentally and during simulation

\section{Conclusions}

The resulting model of thermal processes in the ozonizer allows to see the change in the thermal fields throughout the entire installation over time. Comparison of the theoretical and experimental data showed that the model adequately describes the dynamics of temperature changes in the ozonizer and can be used for further improvement of ozonizers in beekeeping. Analysis of the thermal fields showed that after 2 hours of operation, the discharge device of the ozonizer will heat up above $59^{\circ} \mathrm{C}$, which will seriously affect its performance for ozone. This is especially true for processing bee hives in summer, when the air temperature entering the ozonizer can be more than $30^{\circ} \mathrm{C}$. According to the modelling, in this case the ozonizer will overheat within an hour. In this situation, in our opinion, we should either use several smaller ozonizers instead of one, or change the design of the ozonizer.

\section{References}

[1] Baskakov I.V., Orobinsky V.I., Gulevsky V.A. etc. Studies of the ozonation process when drying grain. IOP Conference Series Earth and Environmental Science, 2020. 9 p. 
[2] Bhatta R., Kayastha R., Subedi D.P., Joshi R. Treatment of Wastewater by Ozone Produced in Dielectric Barrier Discharge. Journal of Chemistry, 2015. 6 p.

[3] Rice R. G. Century 21 - Pregnant with Ozone. Ozone: Science \& Engineering, 2002, vol. 24. pp. $1-15$.

[4] Bin A.K., Roustan M. Mass Transfer in Ozone Reactors. Proc. IOA Int. Specialized Symposium Fundamental and Engineering Concepts for Ozone Reactor Design, Toulouse, France, 2000. pp. 99-131.

[5] Aboltins A., Palabinskis J., Lauva A. Grain active ventilation using ozonized air. Acta Horticulturae, 2010. pp. 449-455.

[6] Granella S. J., Bechlin T. R., Christ D. etc. Improvement of heat \& mass transfer with added ozone into drying air on corn-soy. Engineering in Agriculture, Environment and Food, 2019. 8 p.

[7] Ovsyannikov D.A., Nikolaenko S.A. Mathematical model of heating of the discharge device of an electrical ozonizer. Materials of the fifth All-Russian conference "Energetic- and resource saving technologies and installations". Krasnodar, 2007. pp. 111-115.

[8] Nikolaenko S.A. Parameters of the system of stabilized electrical ozonization of beehives at bee bacteriosis treatment. PhD Eng. thesis. Krasnodar: KubSAU, 2010. - 186 p.

[9] Denisenko E.A. Ozonization modes and parameters of the electric ozonizer for sterilization of plant substrates of forage products. PhD Eng. thesis. Krasnodar; KubSAU, 2013. - 122 p.

[10] Kirko I.M., Kuznetsov V.A. Mathematical model of an barrier electrical ozonizer in hydrodynamic approaching. Physical problems of technology, 1999, No.2. pp. 25-31.

[11] Kutznetsov V.A. Theory and mathematical model of hydrodynamic and electrical processes at intensive regimes of ozonization. PhD Phys.-Math.thesis. Moscow: MSU, 2005. - 244 p.

[12] Lunin V.V., Popovich M.P., Tkachenko S.N. Physical Chemistry of ozone. Moscow: MSU, 1998. $-480 \mathrm{p}$.

[13] Heat Transfer Module User's Guide. COMSOL.

[14]CFD Module User's Guide. COMSOL. 